\title{
SPATIAL PRINCIPLES AND ORNAMENTATION ON WATER GARDEN RELICS OF KESULTANAN CIREBON CASE STUDY: WITANA WATER GARDEN, PAKUNGWATI WATER GARDEN, AND SUNYARAGI WATER GARDEN
}

\author{
${ }^{1}$ Firda Rasyidian Andayani. ${ }^{2}$ Dr. Ir. Yuswadi Saliya, M.Arch. \\ ${ }^{1}$ Student in the Bachelor's (S-1) Study Program in Architecture \\ at Parahyangan Catholic University \\ ${ }^{2}$ Senior lecturer in the Bachelor's (S-1) Study Program in Architecture \\ at Parahyangan Catholic University
}

\begin{abstract}
Water garden is an exterior space of which the main element is water. There is some water garden can be found as a relics of Kesultanan Cirebon. The water gardens in Kesultanan Cirebon are Witana Water Garden, Pakungwati Water Garden, and Sunyaragi Water Garden. Since the era of the Hindusm in Java is already familiar with the concept of a water garden as a sacred bathing place called Petirtaan. But unlike the Hindusm petirtaan, water garden relics of Kesultanan Cirebon has a uniqueness because it is influenced by local and foreign cultures, that can be seen from the concept of spatial principles and ornamentation in water garden.

This study aims to conceive the form of macro spatial principles, micro spatial principles, and ornamentation of each water garden. The macro spatial principles include the cosmology of water gardens. The micro spatial principles include petirtaan shapes. This study also examines the cultural factors that affect each water garden and the relationships of those three water gardens.

This research is hopefully may provide insightful development of knowledge especially related to petirtaan. The analytical method that used in this research is using qualitative approach with descriptiveanalytical based on primary and secondary data. Primary data includes direct observation of the object and secondary data includes literature studies on architecture landsape.

Ancient water garden located in Cirebon has similarity with the Hindu pentirtaan which serves as a sacred ritual place with uniqueness combined with Islamic water garden of Middle East that serves as a place of recreation. It is also can be seen that there is influence from the Chinese culture on Wadasan ornamentation in each water garden. Therefore, Water garden Cirebon has its own uniqueness because of the acculturation of various existing cultures (Hindusm, Islam, dan Chinese). This shows Cirebon is considered a city that is not closed from outside cultural influences.
\end{abstract}

Key Words: Water Garden relics of Kesultanan Cirebon, spatial principles and ornamentation, petirtaan

\section{KONSEP TATA RUANG DAN ORNAMENTASI PADA ARSITEKTUR TAMAN AIR PENINGGALAN KESULTANAN CIREBON STUDI KASUS: TAMAN AIR WITANA, TAMAN AIR PAKUNGWATI, DAN TAMAN AIR SUNYARAGI}

\author{
${ }^{1}$ Firda Rasyidian Andayani. ${ }^{2}$ Dr. Ir. Yuswadi Saliya, M.Arch. \\ ${ }^{1}$ Mahasiswi S1 Program Studi Arsitektur Universitas Katolik Parahyangan \\ ${ }^{2}$ Dosen Pembimbing S1 Program Studi Arsitektur Universitas Katolik Parahyangan
}

\begin{abstract}
Abstrak- Taman air adalah suatu ruang eksterior yang elemen utamanya berupa tatanan elemen air. Beberapa taman air dapat di temukan sebagai peninggalan Kesultanan Cirebon. Taman air tersebut adalah Taman Air Witana, Taman Air Pakungwati, dan Taman Air Sunyaragi. Sejak era kerajaan Hindu di pulau Jawa sudah mengenal konsep taman air sebagai tempat pemandian yang sakral disebut Petirtaan. Namun berbeda dengan

\footnotetext{
${ }^{1}$ Corresponding Author: firdarasyi96@gmail.com
} 
petirtaan Hindu, taman air peninggalan kesultanan Cirebon memiliki keunikan karena dipengaruhi budaya pendatang maupun lokal, yang dapat dilihat dari konsep tata ruang dan ornamentasi taman air.

Penelitian ini bertujuan untuk memahami wujud tata ruang makro, tata ruang mikro, dan ornamentasi dari setiap taman air. Tata ruang makro meliputi kosmologi dari taman air sedangkan tata ruang mikro meliputi sosok bentuk petirtaan. Penelitian ini juga mengkaji faktor-faktor budaya yang mempengaruhi setiap taman air dan hubungan dari ketiga taman tersebut.

Penelitian ini diharapkan dapat memberikan wawasan kepada pengembangan ilmu pengetahuan khususnya yang berkaitan dengan petirtaan. Metode analisis dalam studi menggunakan pendekatan kualitatif secara deskriptif-analitis berdasarkan data primer maupun data sekunder. Data primer mencakup sumber data yang didapat dari pengamatan objek secara langsung dan data sekunder mencakup studi literature mengenai asitektur taman air.

Berdasarkan analisa taman air kuno yang berada di Cirebon memiliki keserupaan dengan petirtaan Hindu yang berfungsi sebagai tempat ritual yang sakral dengan keunikan adanya padu padan dengan taman air Timur Tengah (Islam) yang berfungsi sebagai tempat rekreasi. Selain itu terdapat pengaruh dari budaya Cina yaitu pada ornamentasi Wadasan dan ornamentasi yang ada pada setiap taman air tersebut. Oleh karena itu Taman Air Cirebon memiliki keunikan tersendiri karena adanya akulturasi dari berbagai budaya yang ada (Hindu, Islam, dan Cina). Hal ini menunjukkan Cirebon dinilai kota yang tidak tertutup dari pengaruh budaya luar.

Kata Kunci: Taman Air peninggalan Kesultanan Cirebon, tata ruang dan ornamentasi, petirtaan

\section{PENDAHULUAN}

Kota Cirebon merupakan kota yang berada di pesisir utara Pulau Jawa dan jalur perdagangan lokal maupun internasional tersebut mengalami perpaduan budaya pendatang seperti etnis Timur Tengah (abad-13) dan Cina (abad-14). Oleh karena itu perpaduan antar budaya Cina, Timur Tengah, dan lokal berbaur dengan harmonis pada beberapa objek peninggalan Kesultanan Cirebon terutama pada objek taman air kuno. Arsitektur taman air kuno peninggalan Kesultanan Cirebon terdapat keunikan pada wujud Taman Air Pakungwati (kawasan Keraton Kasepuhan), Taman Air Witana (kawasan Keraton Kanoman), dan Taman Air Sunyaragi, yang diduga memiliki pengaruh dari budaya lokal seperti Hindu dan Jawa dan faktor-faktor budaya pendatang seperti Cina dan Timur Tengah (Islam).

Makna air pada masa pengaruh Hindu di Indonesia sendiri sebagai titik awal kehidupan dan sebuah kesucian yang sakral sehingga terdapat bangunan suci seperti petirtaan. Taman air yang dijadikan objek penelitian ini pun dimungkinkan memiliki konsep yang sama dengan petirtaan yang dibangun pada masa Hindu mengetahui Kota Cirebon pun tidak terlepas dari pemahaman agama Hindu yang sudah cukup lama di Nusantara.

Konsep taman air pada penelitian ini memungkinkan adanya pertimbangan dari penataan ruang ruang makro, tata ruang mikro, dan garis merah yang melandasi konsep tata ruang dan ornamentasi dari ketiga taman air tersebut. Tata ruang makro meliputi kosmologi taman air sedangankan tata ruang mikro meliputi sosok bentuk petirtaan. Selain pentingnya tata ruang, ornamentasi pun mampu menjadi perangkat ruang untuk membantu mengidentifikasi langgam yang mempengaruhi wujud taman air tersebut.

Oleh karena itu peneliti memiliki ketertarikan dalam mendalami konsep mendasar penataan tata ruang dan ornamentasi Arsitektur Taman Air yang ada pada Taman Air Witana, Taman Air Pakungwati dan Taman Air Sunyaragi sebagai taman air peninggalan Kesultanan Cirebon.

Rumusan Masalah, Kota Cirebon yang dipengaruhi oleh budaya etnis China, Islam, Hindu dan Jawa dari objek arsitektur peninggalan Kesultanan Cirebon, tentunya memiliki pengaruh pada konsep penataan Arsitektur taman yang sama-sama menggunakan unsur air dan beberapa ornamentasi pada taman.

Ada pun pertanyaan pada penelitian ini yaitu: 
a. Bagaimana wujud Tata Ruang dan Ornamentasi pada Arsitektur Taman Air peninggalan Kesultanan Cirebon?

b. Apa faktor-faktor budaya yang mendasari wujud taman air?

c. Adakah hubungan konseptual antara setiap Taman Air peninggalan Kesultanan Cirebon?

Lingkup Penelitian, Lingkup penelitian ini mencakup konsep Tata Ruang dan Ornamentasi pada Arsitektur Taman Air peninggalan Kesultanan Cirebon yaitu Taman Air Sunyaragi, Taman Air Pakungwati, dan Taman Air Witana. Tata ruang yang diteliti mencakup skala makro yaitu penataan secara kosmologi kaitan antara ketiga objek tersebut dan skala mikro penataan ruang dalam objek itu sendiri.

Tujuan dan Manfaat Penelitian, Penelitian ini bermaksud untuk mengkaji dan mempelajari konsep yang mendasari tata ruang dan ornamentasi Arsitektur Taman air. Adapun tujuan dari penelitian ini adalah:

a. Memahami wujud Tata Ruang dan Ornamentasi pada Arsitektur Taman Air peninggalan Kesultanan Cirebon

b. Mengidentifikasi faktor-faktor budaya yang mendasari wujud taman air.

c. Mengetahui ada tidaknya hubungan konseptual Taman Air peninggalan Kesultanan Cirebon beserta penyebabnya.

Manfaat dari penelitian ini adalah:

a. Menambah pengetahuan dari konsep tata ruang dan ornamentasi taman air

b. Sebagai acuan penelitian sejenis dan memberikan kontribusi dalam ilmu Arsitektur Taman Air Nusantara

c. Memperkaya khazanah ilmu pengetahuan bagi peneliti dan pembaca bidang Arsitektur Taman Air

\section{KAJIAN TEORI}

\subsection{SEJARAH TAMAN AIR PENINGGALAN KESULTANAN CIREBON}

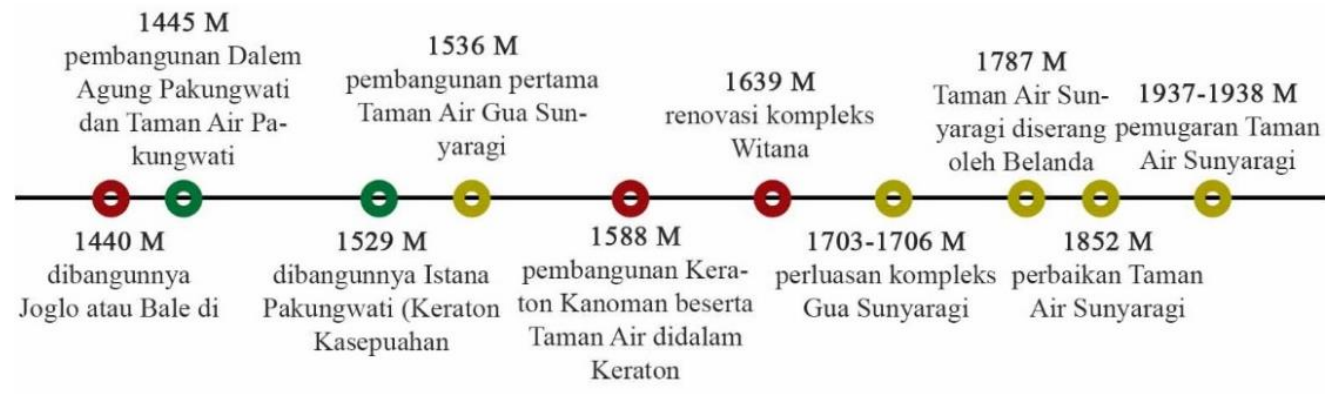

Gambar 1. Sejarah Taman Air peninggalan Kesultanan Cirebon

\subsection{Data Umum Taman Air peninggalan Kesultanan Cirebon}

a. Taman Air Witana 


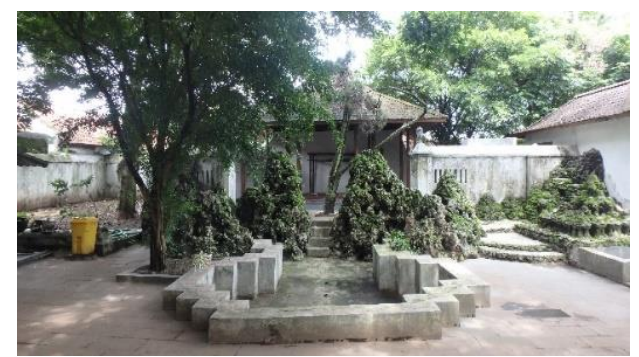

Gambar 2. Taman Air Witana

Nama Objek : Taman Air pada Keraton Kanoman

Lokasi : Komplek Keraton Kanoman, Jalan Winaon Kampung Kanoman, Kanoman, Kota Cirebon, Jawa Barat 45111

Tahun didirikan: 1440-1639

Arsitek : Pangeran Mas Arifin (Era Panembahan Ratu I)

Luas kawasan : 175.500 m2 (Kompleks Keraton)

Fungsi awal : pengintaian garis pantai dan taman spiritual

Orientasi : Timur (garis pantai) - Barat

b. Taman Air Pakungwati

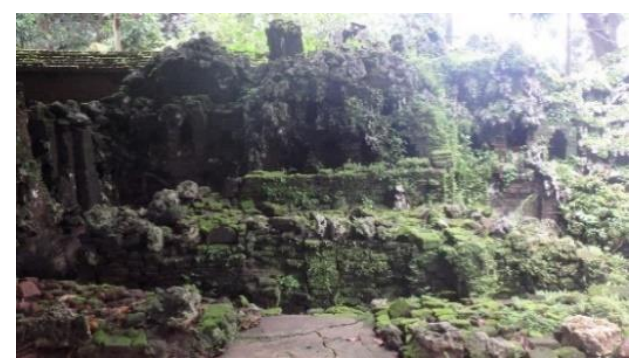

Gambar 3. Taman Air Pakungwati

Nama Objek : Taman Air Pakungwati

Lokasi : Komplek Keraton Kasepuhan, Jalan Kasepuhan No.43, Kesepuhan, Lemahwungkuk, Kota Cirebon, Jawa Barat

Tahun didirikan: 1445

Arsitek : Pangeran Cakrabuana

Luas kawasan : 185.000 m2 (Komplek Keraton)

Fungsi awal : untuk keperluan sehari-hari dan taman spiritual

Orientasi : Utara-Selatan

c. Taman Air Sunyaragi 


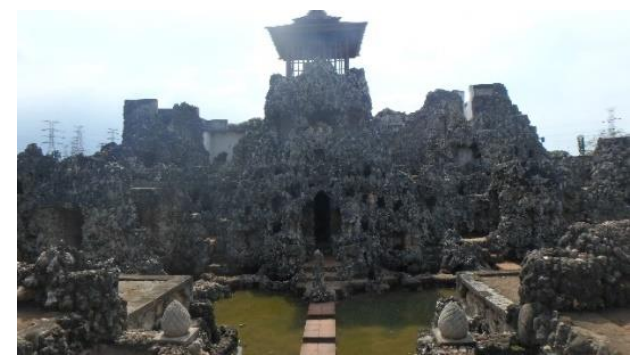

Gambar 4. Taman Air Sunyaragi

Nama Objek : Taman Air Sunyaragi

Lokasi : Sunyaragi, Kesambi, Kota Cirebon 45132

Tahun didirikan: $1536 \mathrm{M}$

Arsitek $\quad$ : -Tahap Awal: Pangeran Mas Zaenal Arifin, Raden Sepat, \& bantuan orang Cina.

-Tahap Kedua: Pangeran Arya Carbon \& Tan Sam Cay

(Arsitek Cina)

-Tahap Ketiga (1852 M): Pangeran Mantang Haji

Luas kawasan : $1800 \mathrm{~m} 2$

Fungsi awal : Taman Rekreasi keluarga Kesultanan Cirebon, taman spiritual, dan tempat berlatih prajurit

Orientasi $\quad$ : Timur - Barat dan Utara-Selatan

\section{METODA PENELITIAN}

Jenis penelitian yang digunakan yaitu metode Kualitatif - Deskriptif dengan melalui proses:

a. Mengajukan interview dengan narasumber

b. Mengumpulkan data yang spesifik

c. Menafsirkan data primer dan data sekunder

Proses pengambilan data telah melalui izin dari Pangeran Kesultanan Cirebon dan staff pengelola dari Keraton dan Taman Air Sunyaragi, dengan pengambilan data selama tiga hari berturut-turut yaitu tanggal 28 Februari - 2 Maret 2018.

\section{ANALISA}

4.1 ANALISA TATA RUANG DAN ORNAMENTASI PADA TAMAN AIR PENINGGALAN KESULTANAN CIREBON

\subsubsection{TATA RUANG MAKRO}

a. Taman Air Witana 


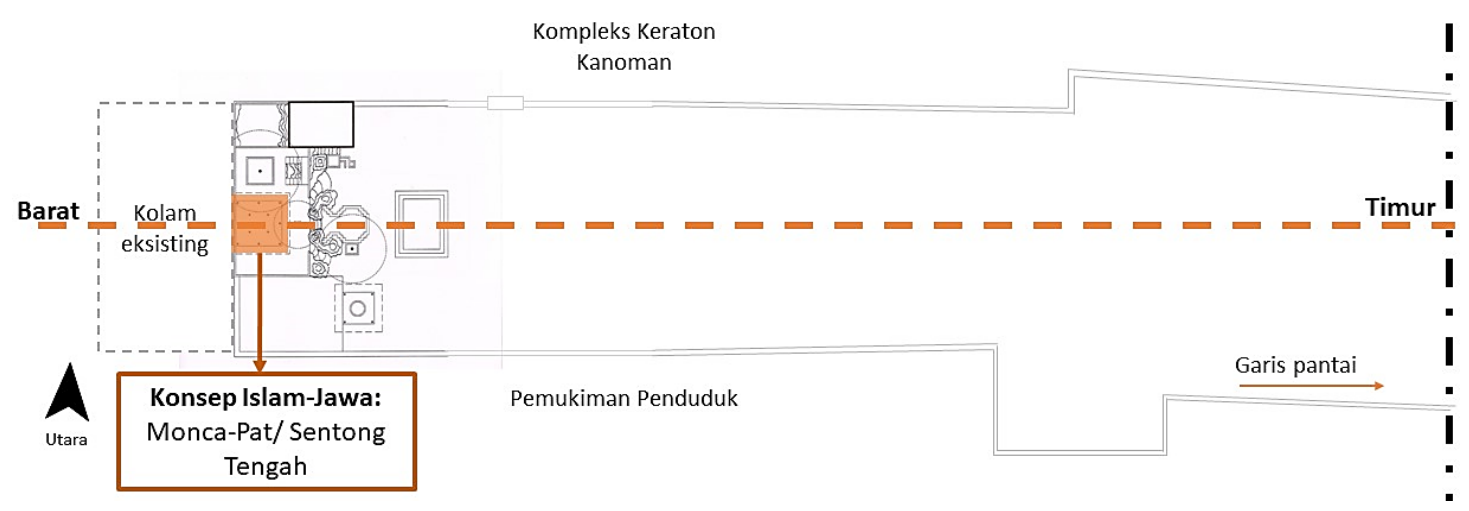

Gambar 5. Analisa Tata Ruang Makro Taman Air Witana

\section{Sumbu}

Orientasi pada Taman Air Witana mengarah ke Timur-Barat dikarenakan taman air pertama kali berfungsi sebagai pengamat garis pantai yang berada di Timur taman air, sehingga sumbu yang ada pada di taman air tidak memiliki pengaruh dari budaya tertentu melainkan karena kondisi tempat dan kepemilikan tanahnya.

\section{Hierarki}

Hierarki pada Taman Air Witana adalah Bale yang ada di belakang taman air tersebut yang berfungsi sebagai meditasi atau tempat bertafakur. Bale ini pun yang paling pertama di bangun di kawasan taman air tersebut dan sebagai tempat yang paling sakral. Berdasarkan dari penataannya, letak Hierarki yang berada dibelakang memiliki keserupaan pada prinsip hierarki Sentong-Tengah ${ }^{2}$ dimana tempat tersebut sangat sakral bagi masyarakat Jawa.

b. Taman Air Pakungwati

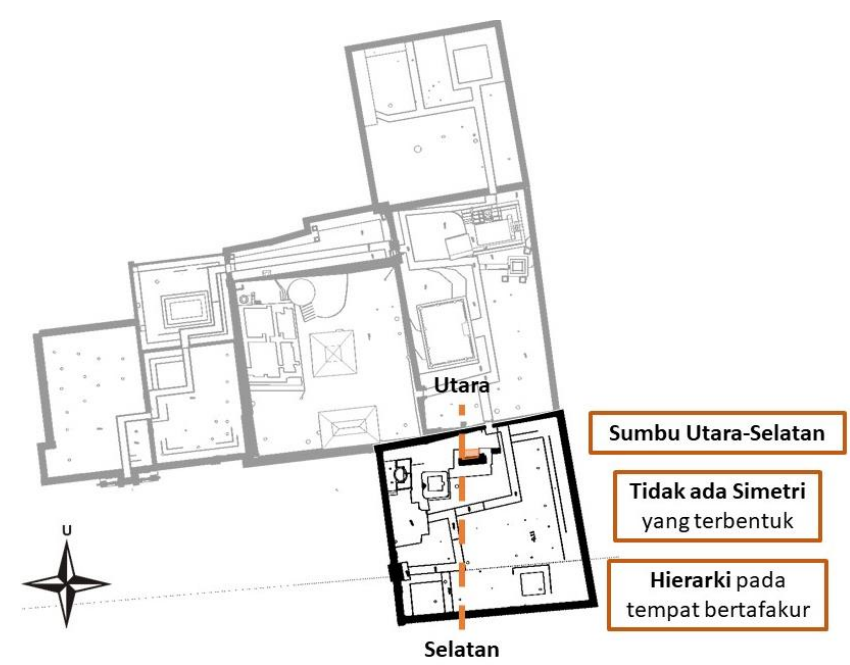

Gambar 6. Analisa Tata Ruang Makro Taman Air Pakungwati

(Sumber: Lokakarya Unpar-STTC, yang telah diolah)

\section{Sumbu}

\footnotetext{
${ }^{2}$ Fauzy, Bachtiar. 2015. Dinamika Akulturasi Arsitektur pada Masjid Sulthoni PlosoKuning di Sleman, Yogyakarta. Disertai tidak diterbitkan. Bandung: Universitas Katolik Parahyangan. p. 27
} 
Sumbu pada taman air mengarah ke Utara-Selatan dan orientasi tersebut tidak ada bukti yang menguatkan adanya konsep budaya tertentu, karena Taman Air Pakungwati yang dibangun pada tahun $1445 \mathrm{M}$ lebih dulu menghadap utara-selatan dari pada masuknya konsep orientasi utara-selatan budaya Islam-Jawa ${ }^{3}$.

Hierarki

Hierarki pada taman air adalah ruang untuk tempat bertafakur pangeran. Berdasarakan susunan hierarkinya tidak mencerminkan pengaruh dari budaya tertentu.

c. Taman Air Sunyaragi

\section{- Kompleks Gua Peteng}

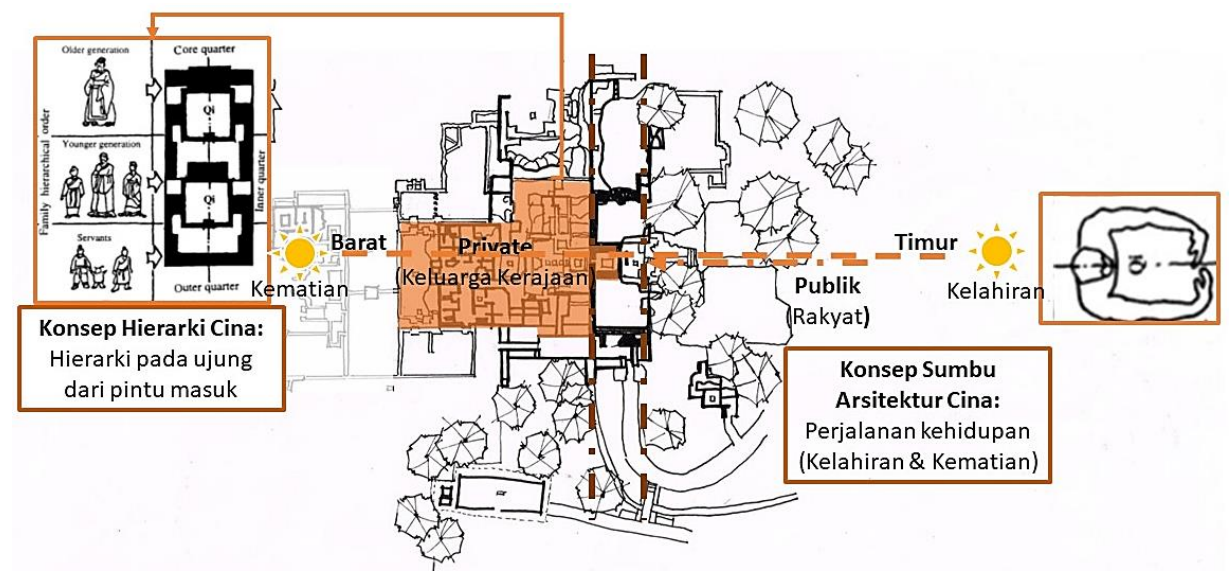

Gambar 7. Analisa Tata Ruang Makro Taman Air Sunyaragi Kompleks Gua Peteng (Sumber: The Origins of Chinese Traditional Architecture, yang telah diolah)

\section{Sumbu}

Sumbu yang terbentuk pada Taman Air Gua Peteng memiliki orientasi TimurBarat dikarenakan mengarah ke Keraton agar pencapaian ke taman tersebut mudah. Namun apabila ditinjau dari teori lainnya, orientasi Timur-Barat sesuai dengan konsep fengshui Arsitektur Cina ${ }^{4}$ dimana melambangkan perjalan hidup manusia yaitu kelahiran (Timur) dan kematian (Barat). Hal ini pun diperkuat dimana komplek Gua Peteng dibangun dengan untuk Putri Ong Tien Nio yang merupakan orang Cina dan dibantu oleh orang-orang Cina pada tahun 1536.

\section{Hierarki}

Hierarki pada taman air ini berada di tengah kawasan Sunyaragi dimana area tersebut memiliki zonasi privat yaitu untuk anggota keluarga Keraton, memiliki kedudukan paling tinggi dari kawasannya, dan kaya akan ornamen sedangkan pada bagian Timur diperuntukkan untuk rakyat. Pembagian Hierarki sebagai berikut serupa dengan konsep Hierarki pada Arsitektur Cina ${ }^{3}$.

\section{-Gua Arga Jumut}

\footnotetext{
${ }^{3}$ Setiawan, Eko. 2000. Konsep Simbolisme Tata Ruang Luar Keraton Surakarta Hadiningrat, Semarang. Disertai tidak diterbitkan. Bandung: Universitas Katolik Parahyangan. p. 32-34

${ }^{4}$ Kustedja, Sugiri. 2012. Fengshui: Elemen Budaya Tionghoa Tradisional. Disertai tidak diterbitkan. Bandung: Universitas Katolik Parahyangan. p. 63-65
} 


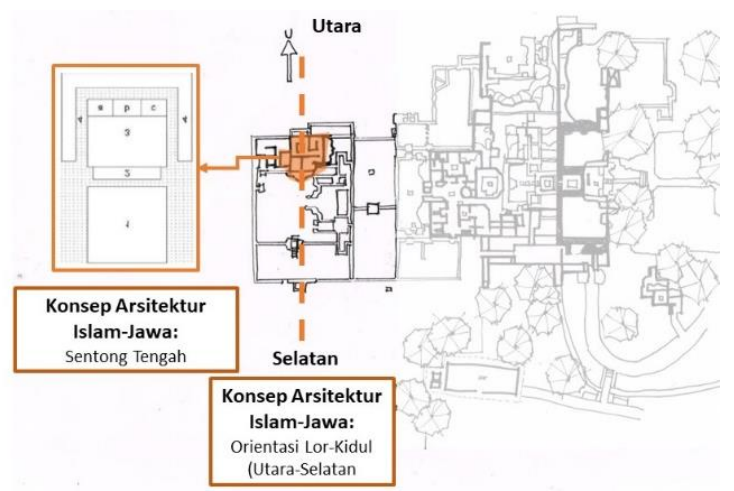

Gambar 8. Analisa Tata Ruang Makro Taman Air Sunyaragi Gua Arga Jumut (Sumber: jonathansimanjuntak. wordpress, yang telah diolah)

\section{Sumbu}

Sumbu pada taman air ini memiliki orientasi Utara-Selatan dengan penataan linear antara gapura candi bentar-lapangan luas-bangunan induk yaitu Gua Arga Jumut. Panataan ini serupa dengan tatanan Islam-Jawa dimana pada saat pembangunannya yaitu tahun 1703 sudah memasuki Era Islam di Jawa yang ditandai dengan orientasiorientasi kompleks keraton yang menghadap Utara-Selatan ${ }^{2}$ dan makam Sunan Gunung Jati.

\section{Hierarki}

Hierarki pada taman air ini berada di bagian ujung dari kawasan seperti pada Konsep Sentong Tengah pada penataan Arsitektur Islam-Jawa, dimana tempat tersebut adalah tempat sakral, hal itu pun diperkuat dengan adanya kolam petirtaan pada taman air tersebut dimana tempat untuk meditasi.

\subsubsection{TATA RUANG MIKRO}

\section{a. Taman Air Witana}

Jenis Petirtaan ${ }^{4}$

Taman Air Witana termasuk kedalam jenis Petirtaan Profane yaitu kolam Witana dibelakang taman air digunakan sebagai keluarga kerajaan untuk bermain air dan Petirtaan untuk mendukung aktivitas keagamaan yaitu meditasi pada bangunan Langgar Alit.

\section{Bentuk Petirtaan}

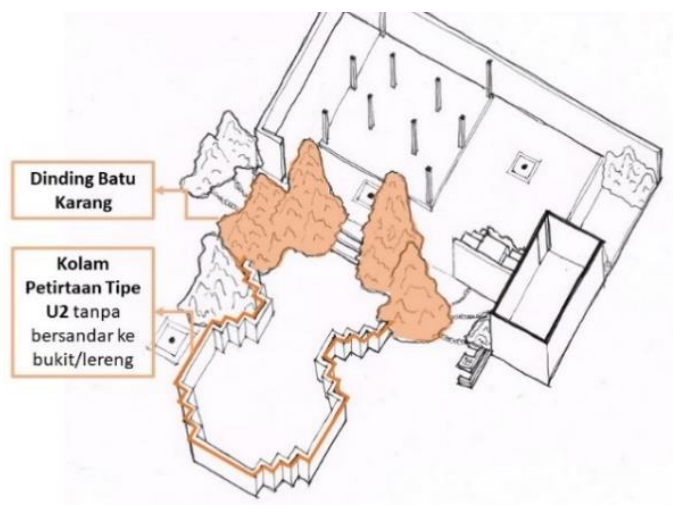

Gambar 9. Analisa Tata Ruang Mikro Taman Air Witana

\section{Pembagian Kamar}




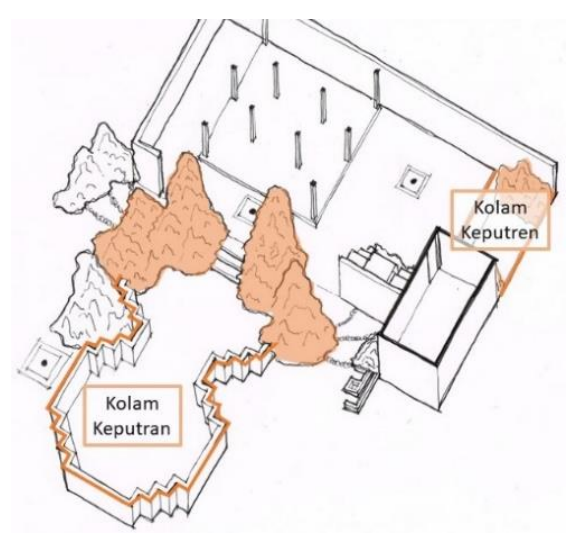

Gambar 10. Analisa Tata Ruang Mikro Taman Air Witana

b. Taman Air Pakungwati

Jenis Petirtaan ${ }^{4}$

Jenis petirtaan pada Taman Air Pakungwati termasuk petirtaan profane yaitu untuk tempat keputren bermain dan petirtaan yang mendukung kegiatan keagamaan yaitu untuk tempat bertafakur.

\section{Bentuk Petirtaan}

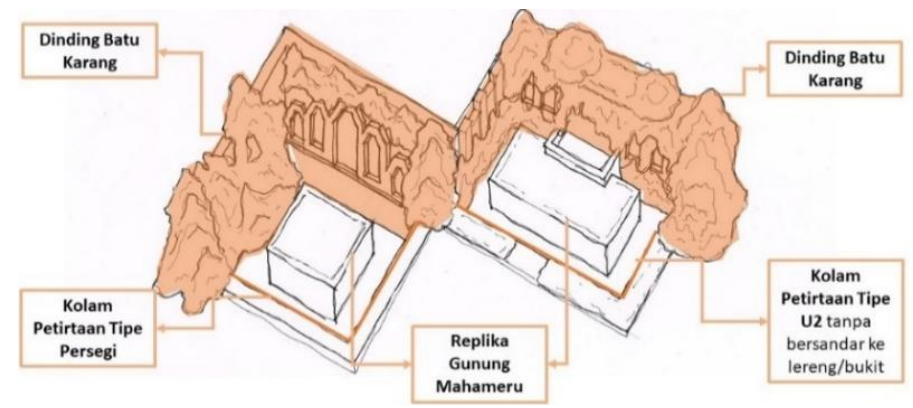

Gambar 11. Analisa Tata Ruang Mikro Taman Air Pakungwati

\section{Pembagian Kamar}

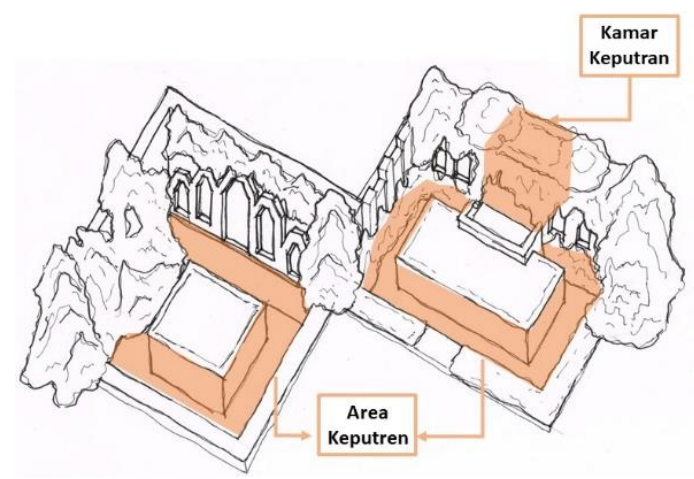

Gambar 12. Analisa Tata Ruang Mikro Taman Air Pakungwati

\section{c. Taman Air Sunyaragi Jenis Petirtaan ${ }^{5}$}

\footnotetext{
${ }^{5}$ Prajudi, Herwindo. 2015. Kajian Arsitektur Percandian Petirtaan di Jawa (Identifikasi). Disertai tidak diterbitkan. Bandung: Universitas Katolik Parahyangan.
} 
Jenis petirtaan pada taman air ini adalah petirtaan profane yaitu untuk rekreasi keluarga keraton serta tamunya dan untuk mendukung aktivitas keagamaan yaitu tafakur atau meditasi.

Bentuk Petirtaan

- Kompleks Gua Peteng

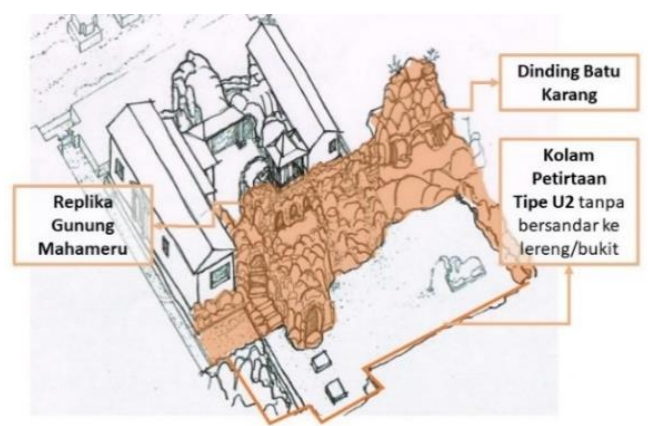

Gambar 13. Analisa Tata Ruang Mikro Taman Air Snyaragi

\section{-Gua Arga Jumut}

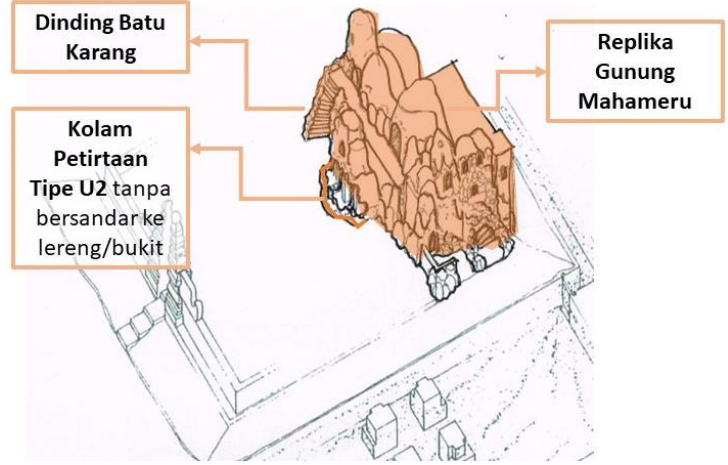

Gambar 14. Analisa Tata Ruang Mikro Taman Air Sunyaragi

\section{Pembagian Kamar}

\section{- Kompleks Gua Peteng}

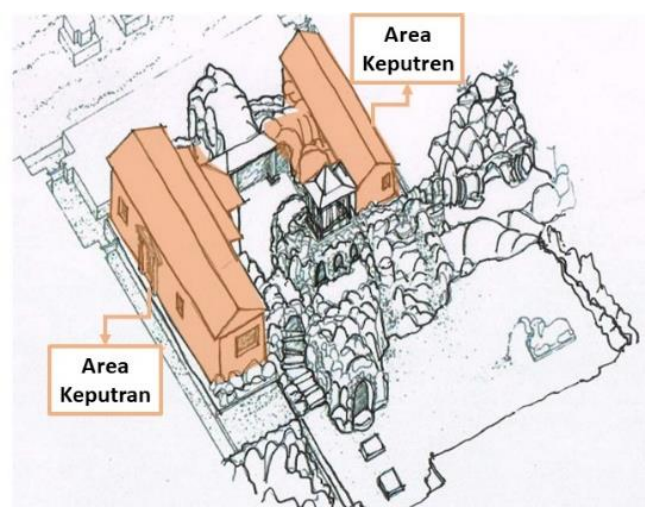

Gambar 15. Analisa Tata Ruang Mikro Taman Air Sunyaragi

\section{-Gua Arga Jumut}




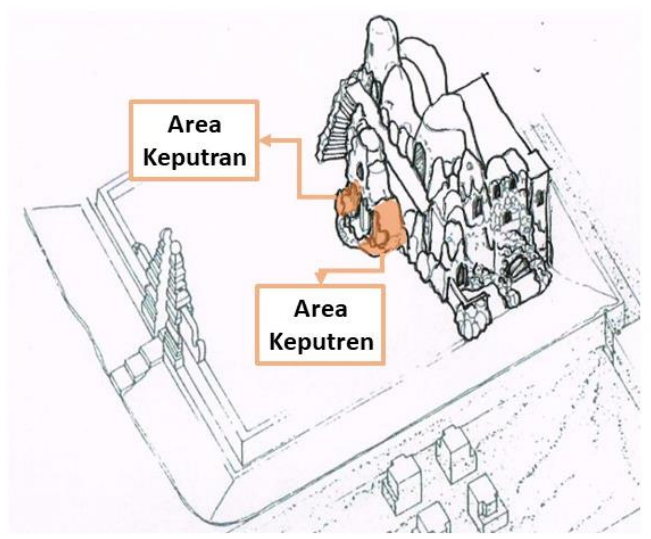

Gambar 16. Analisa Tata Ruang Mikro Taman Air Sunyaragi

\subsubsection{ORNAMENTASI}

a. Taman Air Witana

- Hindu

\section{Bentuk denah Candi}

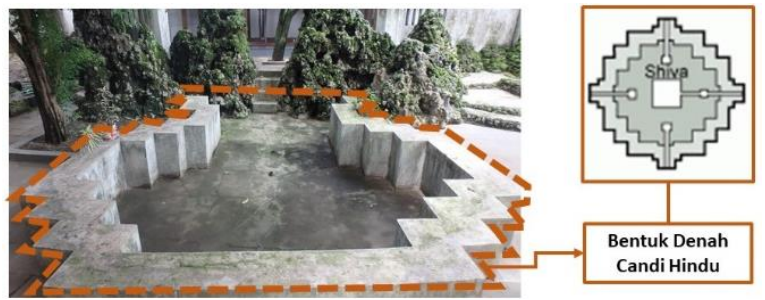

Gambar 17. Analisa Ornamentasi Hindu Taman Air Witana (Sumber: belajar.kemdikbud.go.id, yang telah diolah)

- Hindu dan Cina

\section{Candi Bentar}

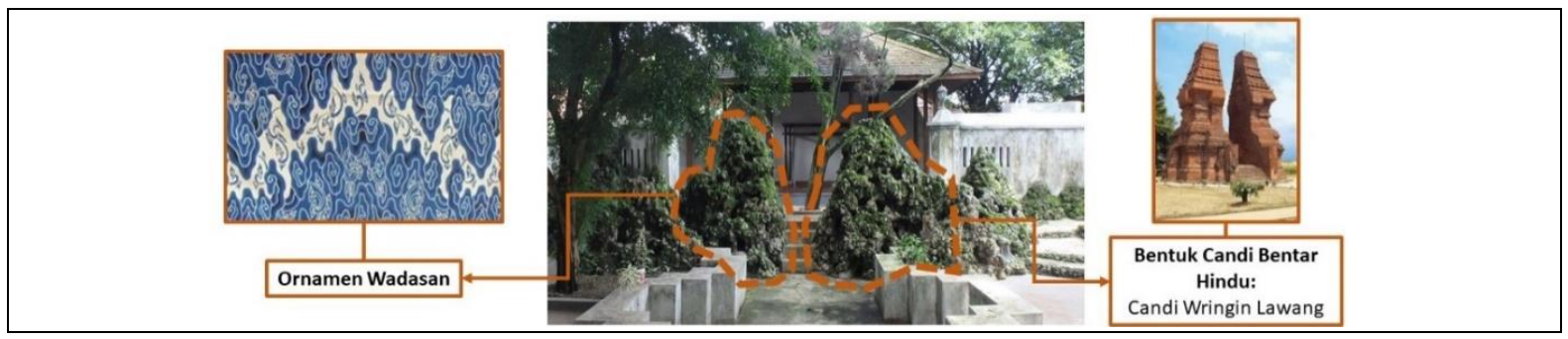

\section{Replika Mahameru}

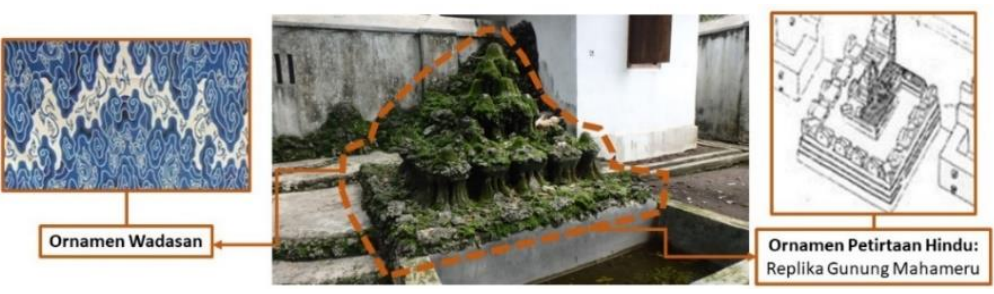


b. Taman Air Pakungwati

- Hindu

\section{Replika Mahameru}
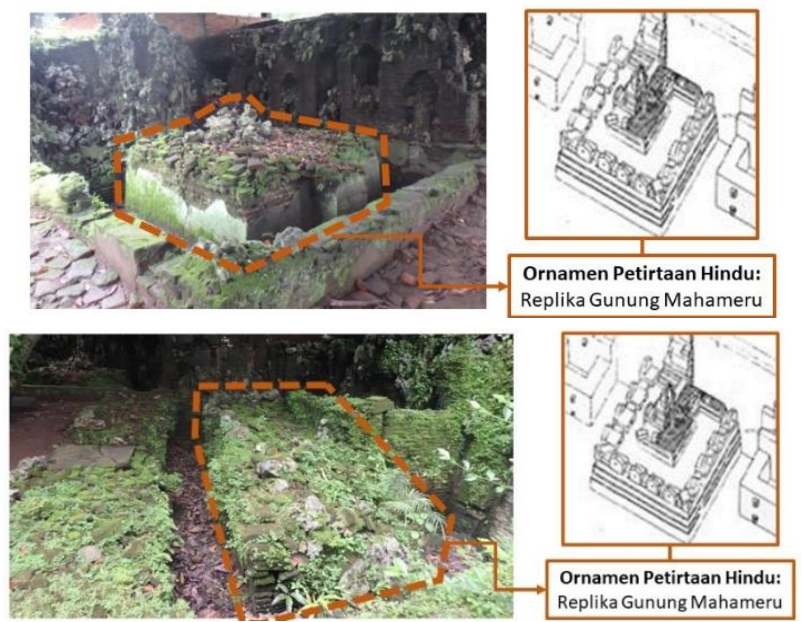

\section{Relung Candi}
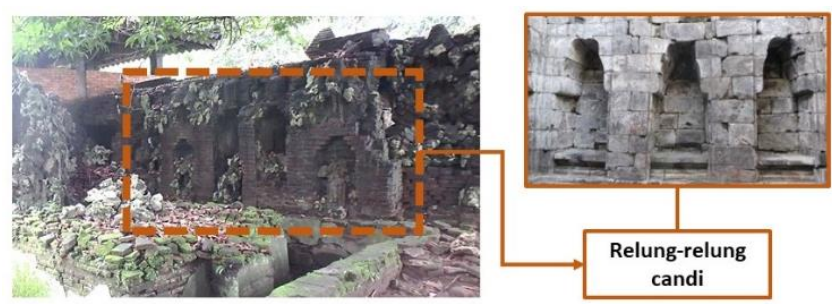

Gambar 19. Analisa Ornamentasi Hindu Taman Air Pakungwati (Sumber: tripadvisor.co.uk, yang telah diolah)

- Cina

\section{Wadasan}

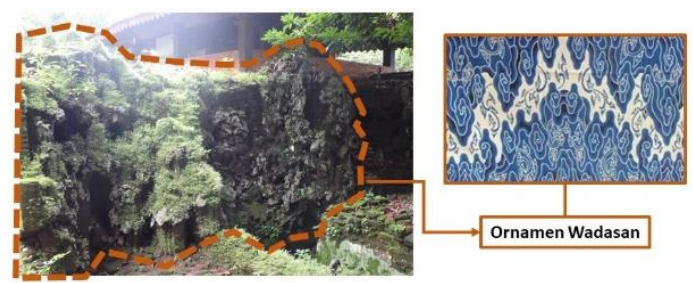

Gambar 20. Analisa Ornamentasi Cina Taman Air Pakungwati (Sumber: i.pinimg.com, yang telah diolah)

c. Taman Air Sunyaragi

- Hindu

\section{Replika Mahameru}




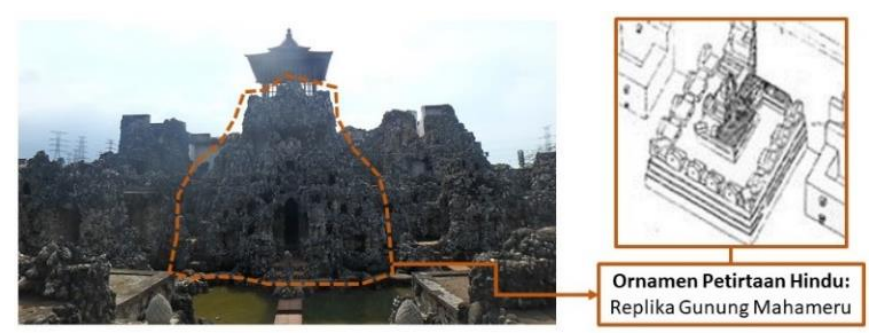

Miniatur Candi/ Paduraksa

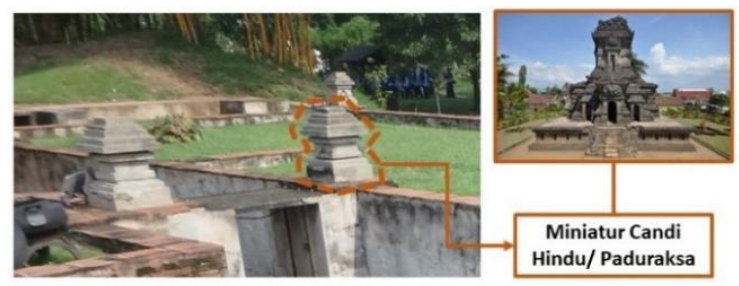

\section{Relung Candi}
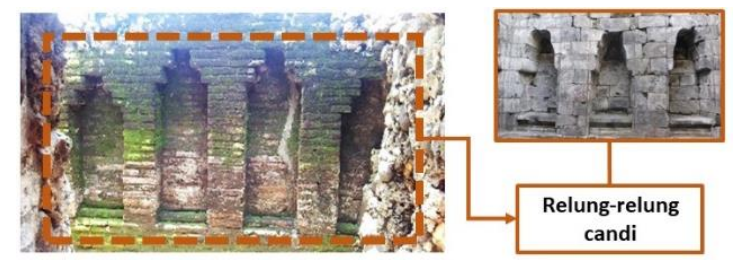

Gambar 21. Analisa Ornamentasi Hindu Taman Air Sunyaragi (Sumber: Rahadhian P.H, yang telah diolah

- Cina

\section{Wadasan}

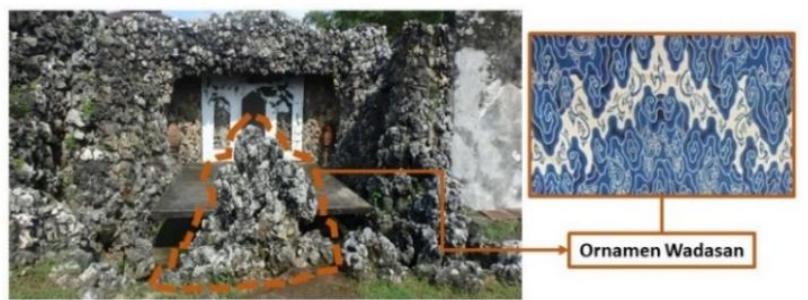

Gambar 22. Analisa Ornamentasi Cina Taman Air Sunyaragi (Sumber: i.pinimg.com, yang telah diolah)

\subsection{HASIL KOMPARASI TATA RUANG DAN ORNAMENTASI PADA TAMAN AIR PENINGGALAN KESULTANAN CIREBON}

\subsubsection{TATA RUANG MAKRO}

1. Taman Air Witana 


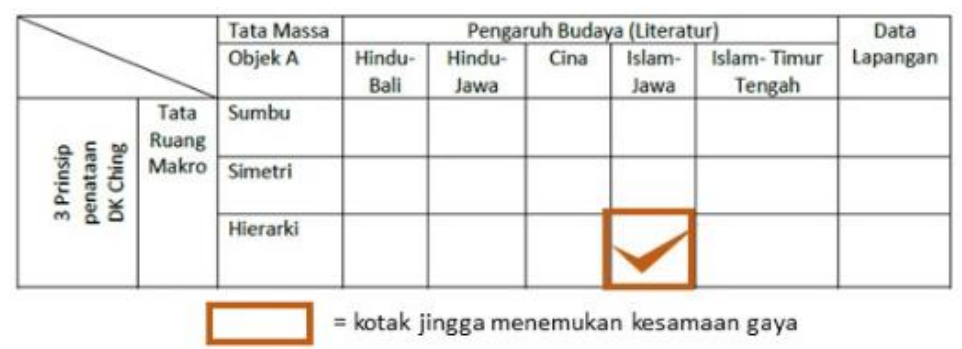

2. Taman Air Pakungwati

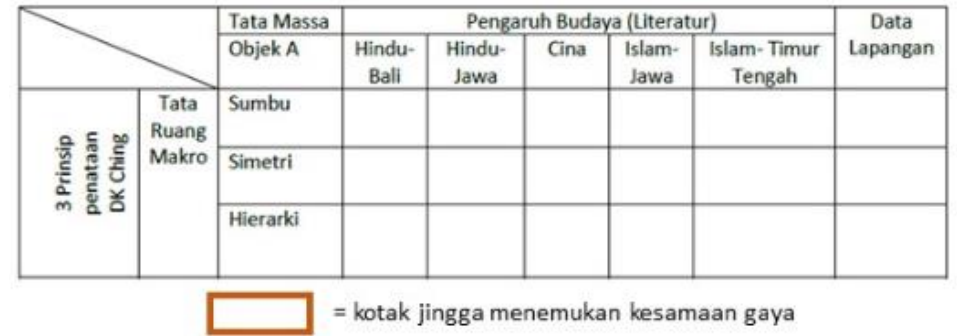

3. Taman Air Sunyaragi

Taman Air Gua Peteng

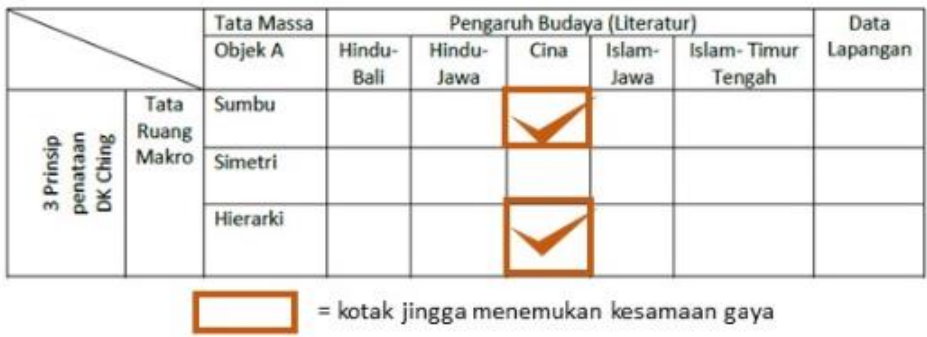

Taman Air Gua Arga Jumut

\begin{tabular}{|c|c|c|c|c|c|c|c|c|}
\hline & Tata Massa & \multicolumn{5}{|c|}{ Pengaruh Budaya (Literatur) } & \multirow{2}{*}{$\begin{array}{c}\text { Data } \\
\text { Lapangan }\end{array}$} \\
\hline & & Objek A & $\begin{array}{l}\text { Hindu- } \\
\text { Bali }\end{array}$ & $\begin{array}{l}\text { Hindu- } \\
\text { Jawa }\end{array}$ & Cina & $\begin{array}{l}\text { Islam- } \\
\text { Jawa }\end{array}$ & $\begin{array}{c}\text { Islam- Timur } \\
\text { Tengah }\end{array}$ & \\
\hline \multirow{3}{*}{ 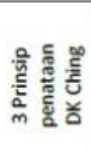 } & \multirow{3}{*}{$\begin{array}{c}\text { Tata } \\
\text { Ruang } \\
\text { Makro }\end{array}$} & Sumbu & & & & & & \\
\hline & & Simetri & & & & & & \\
\hline & & Hierarki & & & & & & \\
\hline
\end{tabular}

Hasil komparasi Tata Ruang Makro pada ketiga taman air peninggalan kesultanan Cirebon tersebut menunjukkan bahwa ketiga taman air tersebut tidak memiliki benang merah dari penataannya hal ini dikarenakan masing-masing taman air memiliki pertimbangan dari kondisi lokasi dan rentan waktu yang jauh. Akan tetapi pengembangan konsep tata ruang makro taman air peninggalan Kesultanan Cirebon semakin dipertimbangkan pada pembangunan Taman Air Sunyaragi dimana memiliki konsep Arsitektur Cina dan Islam-Jawa. 


\subsubsection{TATA RUANG MIKRO}

1. Taman Air Witana

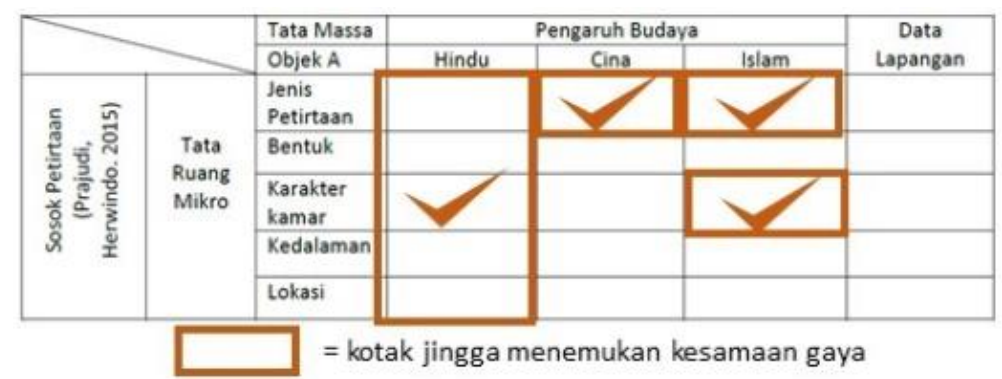

2. Taman Air Pakungwati

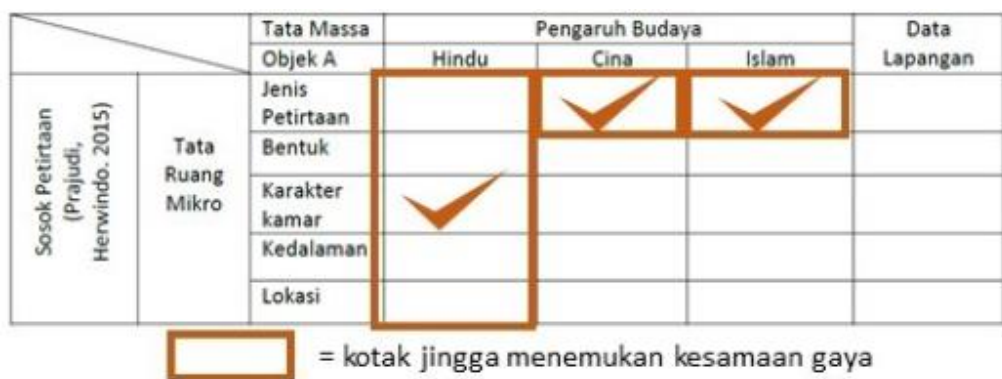

3. Taman Air Sunyaragi

\section{Taman Air Gua Peteng}

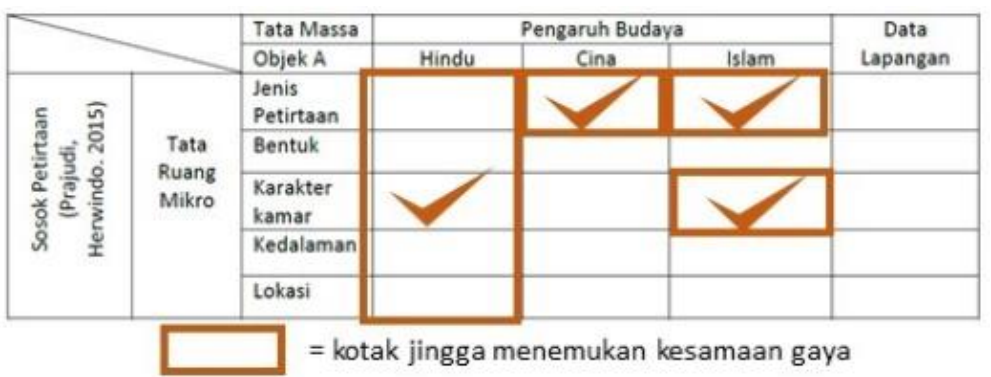

\section{Taman Air Gua Arga Jumut}

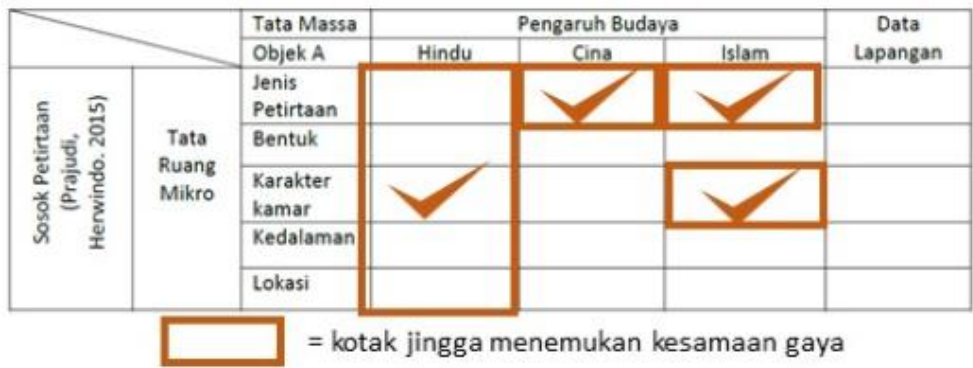

Hasil komparasi Tata Ruang Mikro pada ketiga taman air peninggalan Kesultanan Cirebon menunjukkan keserupaan pada petirtaan Hindu dan dipengaruhi oleh nilai kelokalan 
seperti penggunaan dinding batu karang karena Cirebon merupakan kota Pesisir, berbeda dengan petirtaan Hindu yang pada umumnya menggunakan material percandian seperti batu Andesit.

Kemudian dapat ditemukan bahwa taman air kuno di Cirebon merupakan taman air Hindu yang dipadu padankan dengan taman air Islam dan Cina sehingga sebagai tempat ritual sakral dan rekreasi. Sedangkan jenis taman air Cina didukung dengan adanya elemen wadasan sebagai representasi alam. Kemudian dapat disimpulkan bahwa unsur air ada kaitannya dengan wanita seperti pada ketiga taman air tersebut letaknya berada di keputren atau area keputren memiliki unsur air didalamnya, hal ini dikarenakan yoni yang melambangkan wanita adalah simbol kesuburan, begitu juga unsur air dalam pemahaman Hindu sebagai kesuburan tanah, ehingga air dan wanita adalah simbol dari kesuburan tanah untuk meningkatkan hasil panen maupun kesuburan manusia agar dikaruniai keturunan yang banyak.

\subsubsection{ORNAMENTASI}

1. Taman Air Witana

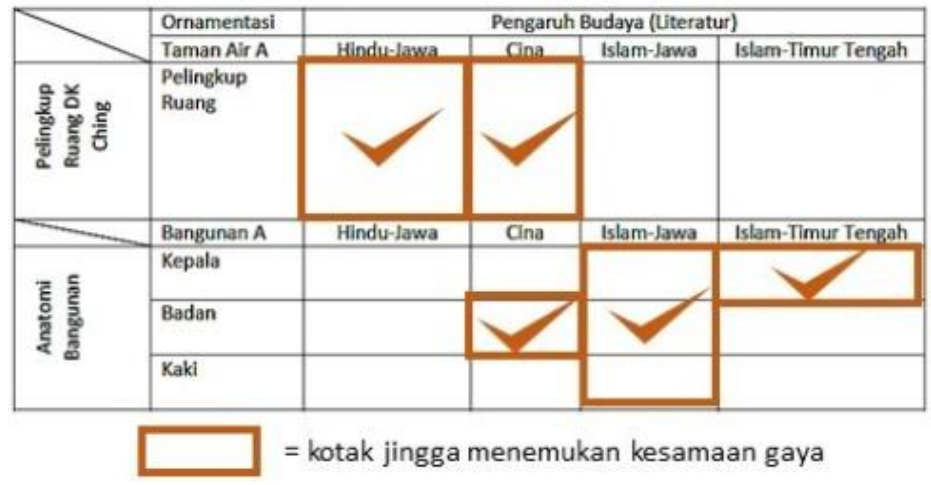

2. Taman Air Pakungwati

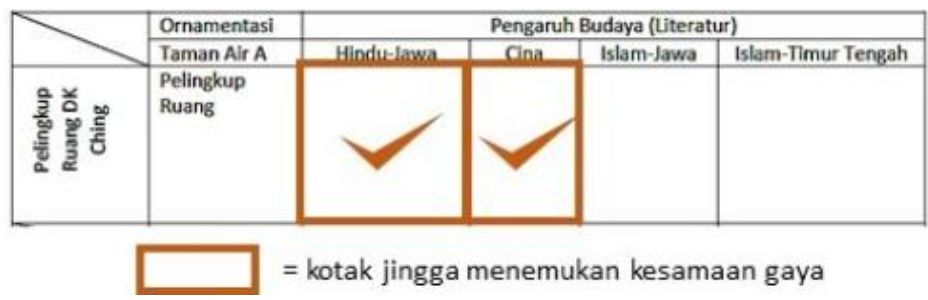

3. Taman Air Sunyaragi

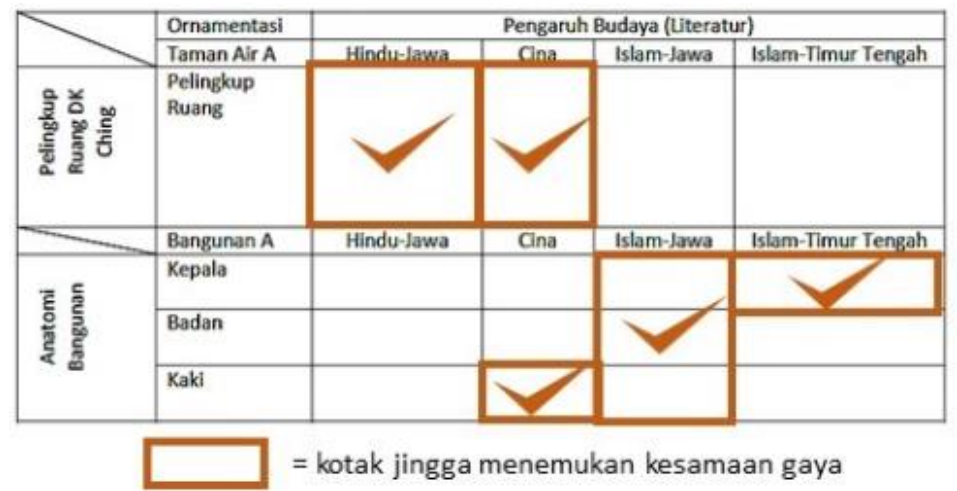




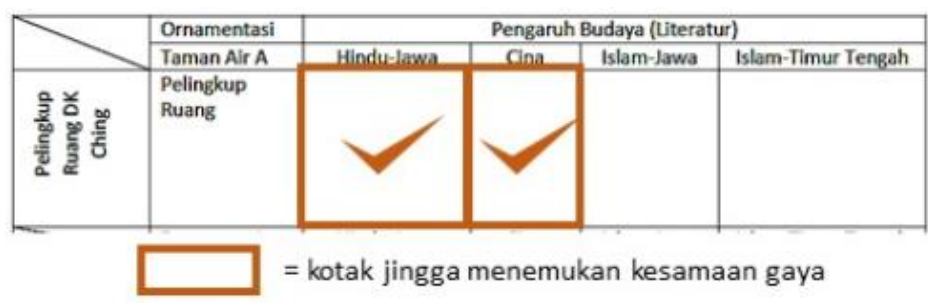

Hasil komparasi ornamentasi pada ketiga taman air kesultanan Cirebon tersebut menunjukkan prinsip penggunaan ornamen yang sama pada pelingkup ruang taman air yaitu ornamentasi wadasan dan replika Mahameru. Ornamentasi wadasan sendiri dipengaruhi oleh budaya Cina dan ornamentasi replika Mahameru pengaruh dari budaya Hindu-Jawa. Sedangkan bangunan Joglo disekitar taman air dominan memiliki pengaruh dari ornamentasi tradisional Jawa atau Islam-Jawa.

\section{KESIMPULAN}

Berdasarkan data masing-masing Taman Air yang sudah dianalisis, dapat ditarik kesimpulan yang berangkat dari pertanyaan peneliatan, yaitu:

Bagaimana wujud Tata Ruang dan Ornamentasi pada Arsitektur Taman Air peninggalan Kesultanan Cirebon? Dan apa faktor-faktor budaya yang mendasari wujud taman air?

Wujud dari taman air peninggalan kesultanan Cirebon secara tata ruang makro tidak ada korelasi tatanan yang serupa dari ketiga objeknya namun terdapat prinsip yang sama pada tata ruang mikro. Tata ruang mikro tersebut serupa dengan petirtaan Hindu dengan wujud yang dipengaruh budaya lokal dan Cina seperti pada ornamentasi Wadasan. Selain ornamen Wadasan, ornamentasi disetiap taman air terdapat ornamen replika Mahameru yang merupakan pengaruh dari Hindu. Berdasarkan fungsinya Taman Air tersebut memiliki perpaduan antara Harem (Islam) dan Hindu atau sebagai tempat rekreasi dan ritual. Hal ini menunjukkan Cirebon tidak tertutup pada pengaruh budaya luar.

Kemudian terdapat pertanyaan lainnya, yaitu:

\section{Cirebon?}

Adakah hubungan konseptual antara setiap Taman Air peninggalan Kesultanan

Ada, hubungan dari setiap taman air peninggalan Kesultanan Cirebon sama-sama memiliki persistensi bentuk petirtaan Hindu namun dengan tata cara budaya Islam dan dipadu padankan dengan budaya lokal dan Cina yaitu ornamen wadasan. Namun tata ruang makro seperti sumbu orientasi dan hierarki masing-masing berbeda karena pertimbangan lokasi tempat, kepemilikan lahan, mahzab yang membangun taman air, dan juga sejarah rentan waktu yang cukup jauh. Selain itu fungsi dari setiap taman air memiliki persamaan fungsi dan pengolahan air yang terus mengalir (tidak dalam keadaan diam).

Kehadiran air dalam penataan ruang berkaitan dengan 'wanita' yang dilihat dari lokasinya berada di area keputrean atau setiap area keputren terdapat unsur air, sehingga dapat ditarik kesimpulan unsur air memiliki hubungan dengan wanita. Hal ini dikarenakan Yoni yang melambangkan wanita adalah simbol kesuburan, begitu juga unsur air dalam pemahaman Hindu sebagai kesuburan tanah. Oleh karena itu air dan wanita adalah simbol dari kesuburan tanah untuk meningkatkan hasil panen maupun kesuburan manusia agar dikaruniai keturunan yang banyak.

\subsection{SARAN}


Penelitian mengenai konsep Arsitektur Taman Air pada khazanah ilmu Arsitektur diaggap masih minim di Indonesia sendiri, sehingga penelitian tentang tata ruang dan ornamentasi pada Arsitektur Taman Air peninggalan Kesultanan Cirebon diharapkan dapat menjadi sumbangan ilmu pengetahuan khususnya tentang petirtaan kuno di Indonesia. Diharapkan pula penelitian ini dapat dikembangkan lebih jauh dari salah satu objek maupun ketiga objek ini yang kemudian dapat dikorelasikan dengan aspek lain maupun penelitian yang sama tentang tata ruang dan ornamentasi Arsitektur Taman Air.

Kesimpulan pada penelitian ini berdasarkan sejauh data-data yang diperoleh selama penelitian sehingga kesimpulan tentang konsep tata ruang dan ornamentasi pada taman air peninggalan kesultanan Cirebon kemungkinan akan berubah bila terdapat data-data terbaru yang lebih akurat.

\section{DAFTAR PUSTAKA}

\section{Buku yang diterbitkan:}

Amin, Jusna J.A. 2016. Mengenal Arsitektur Lansekap Nusantara. Yogyakarta: Pustaka Pelajar.

Bloultz, Elizabeth \& Chip Sullivan. 2010. Ilustrated History of Landscape Design. New Jersey: John Willey \& Son, Inc.

Ching, Francis D.K. 1979. Arsitektur: Bentuk, Ruang, dan Tatanan. New York: Litton Educational Publishing, Inc.

Lombard, Denys. 2010. Gardens in Java. Bogor: Percetakan Grafika Mardi Yuana.

Verster, Jen. 1991. Keraton-keraton Cirebon. Rotterdam: Coks Prins nBO.

\section{Buku yang tidak diterbitkan:}

Ansari, Nazia. 2011. The Islamic Garden. Makalah tidak di publikasi dan disajikan pada Departemen of Landscape CEPT University, Gujarat, India.

Fauzy, Bachtiar. 2015. Dinamika Akulturasi Arsitektur pada Masjid Sulthoni PlosoKuning di Sleman, Yogyakarta. Disertai tidak diterbitkan. Bandung: Universitas Katolik Parahyangan.

Kustedja, Sugiri. 2012. Fengshui: Elemen Budaya Tionghoa Tradisional. Disertai tidak diterbitkan. Bandung: Universitas Katolik Parahyangan.

Prajudi, Rahadhian. 2015. Kajian Arsitektur Percandian Petirtaan di Jawa (Identifikasi). Disertai tidak diterbitkan. Bandung: Universitas Katolik Parahyangan.

Herwindo, R. P. 1999. Kajian Tipo-morfologi Arsitektur Candi di Jawa, Buku 1. Thesis Arsitektur Institut Teknologi Bandung.

Zhang, Donia. 2018. Classical Chinese Gardens: Landscapes for Self-Cultivation. Jurnal tidak di publikasi dan disajikan pada Contemporary Urban Affairs, Oxford Brookes University, UK.

\section{Sumber pendukung:}

www.allchinanet.com/chinese_garden/classical_chinese_gardens

https://hurahura.wordpress.com/2011/01/01/patirthan-di-pawitra-jalatunda-dan-belahan/

https://kebudayaan.kemdikbud.go.id/bpcbbanten/2017/02/09/makna-air-pada-masa-pengaruh-hindubuddha-di-indonesia/

https://www.ecomena.org/garden-islamic-culture/

http://www.kangkamal.com/2012/09/ornamen.html

http://blog-senirupa.tumblr.com/post/60359055053/ragam-motif-hias-klasik-tradisional

http://inputbali.com/budaya-bali/asta-kosala-kosali-fengshui-tata-ruang bangunan-bali

http://history-of-hinduism.blogspot.co.id/2010/06/water-and-hinduism.html 